\title{
SECONDARY MOMENTS DUE TO PRESTRESSING WITH DIFFERENT BOND AT THE ULTIMATE LIMIT STATE
}

\author{
Jaroslav HALVONÍK ${ }^{1 *}$, Peter PAŽMA ${ }^{1}$, Radoslav VIDA ${ }^{1}$
}

\section{Abstract}

Secondary effects of prestressing develop in statically indeterminate structures (e.g., continuous beams) due to the restraint of deformations imposed by hyperstatic restraints. These effects may significantly influence internal forces and stresses in prestressed structures. Secondary effects are influenced by the redundancy of a structural system, which raises the question of whether they will remain constant after a change in the structural system, e.g., due to the development of plastic hinge(s) in a critical cross-section(s) or after the development of a kinematic mechanism, or if they will disappear when the structure changes into a sequence of simply supported beams. The paper deals with an investigation of the behavior of continuous post-tensioned beams subjected to an ultimate load with significant secondary effects from prestressing. A total of 6 two-span beams prestressed by tendons with different bonds were tested in a laboratory with a load that changed their structural system into a kinematic mechanism. The internal forces and secondary effects of the prestressing were controlled through measurements of the reactions in all the supports. The results revealed that the secondary effects remained as a permanent part of the action on the experimental beams, even after the development of the kinematic mechanism. The results obtained confirmed that secondary effects should be included in all combinations of actions for verifications of ultimate limit states (ULS).

\section{Address}

1 Faculty of Civil Engineering, Slovak University of Technology in Bratislava, Slovak Republic

* Corresponding author: jaroslav.halvonik@stuba.sk

\section{Key words}

- Prestressed concrete

- Secondary moments,

- Plastic hinges,

- Kinematic mechanism

\section{INTRODUCTION}

Hyperstatic prestressed concrete beams are typical structures in bridge engineering. The first method for designing such structures were based on a theory of allowable stresses. Controls of stresses in structural materials were used for both safety verifications and controls of serviceability. The stresses were checked with simple combinations of actions based on service (unfactored) loads without the development of plastic deformations in structural materials (concrete, steel). The design of prestressed structures became more complex due to the introduction of the theory of limit states in design codes. The serviceability and durability are still controlled with the effects of combinations composed of service loads; however, structural safety has to be verified with so-called design combinations of actions, which include factored loads and resistances that are assessed with an assumption of the plastic behavior of structural materials. This assumption leads many times to the development of plastic hinges and changes in the structural scheme at the ultimate limit state (ULS). 
The tendon layout in prestressed beams usually complies with the distribution of internal forces due to the load, e.g., in a simply supported beam, the tendons are located in the bottom part, while in a continuous beam, they usually have a polygonal arrangement, which means that in areas with sagging moments, they are located at the bottom, while in areas with hogging moments, they are on the top. The reason for this is that the bending moment due to the prestressing is proportional to the distance " $e$ " between the center of gravity of the prestressing unit and the beam. Product $P \times e$ then represents the primary effect of the prestressing. However, in the case of hyperstatic structural systems, prestressing generates additional secondary effects, which may significantly influence the distribution of the internal forces in the beam. The secondary effects depend on the structural system as well as on the geometry of a tendon. They can even be equal to zero in hyperstatic structures in the case of a suitable tendon geometry, i.e., a concordant tendon. A detailed determination of concordant tendons was described by Burgoyne (2005). However, in most cases the secondary effects accompany the primary effects of the prestressing. As has already been mentioned, the secondary effects depend on the structural system of the member, so they should be influenced by a change in the structural system. Therefore, it raises the question as to whether the secondary effects will remain unchanged in a structure after a change in its structural system, or if we should omit these effects in an assessment of the bending capacity at the ULS. In most cases, the ultimate moment capacities are checked on a section-by-section basis by applying the factored values of the elastic load distribution. Some codes make no mention of secondary moments, but others allow for the inclusion of the secondary moment $M_{2}$ in the ultimate load calculations (Mattock 1983). This condition ensures that the first plastic hinge forms with a sufficient reserve of strength. Up to this load, the structure has been behaving elastically, so secondary moments would indeed have been present. In a beam with sagging secondary moments, the effect can reduce the required ultimate moment capacity that has to be provided over the piers and increase the moment capacity that is required in the span regions. It can be concluded that the secondary effects of prestressing can influence the safety of a structure.

The objective is to examine the behavior of hyperstatic structures prestressed with tendons that produce secondary effects. An experimental investigation has been carried out with 6 post-tensioned twospan continuous beams with a loading that was gradually increased to the ultimate level. The second goal of the experimental campaign was focused on an investigation of the behavior of beams prestressed by tendons with different bonds. The first group of beams was prestressed by fully bonded tendons, the second group by tendons protected with anti-corrosion protection based on oil emulsions, and the last one prestressed by unbonded tendons (monostrands).

\section{DESCRIPTION OF THE EXPERIMENTAL PROGRAM}

Six normal beams and one trial beam were cast for the experiment with the same cross-section dimensions of $0.25 \times 0.4 \mathrm{~m}$ and a length of $10.5 \mathrm{~m}$. The trial beam was tested with the intention of finding all the mistakes and errors which may have occurred in the design and during the installation and loading of the experimental beams. The results obtained have not been used for any further analysis.

Concrete with a strength class of $\mathrm{C} 40 / 50$ (cylinder/cube strength in $\mathrm{MPa}$ ) was used. The beams were produced in the specialized factory of ZIPP Bratislava, Ltd., Sered' division. The pictures taken during the preparation and execution of the beams are in Fig.1. The beams were then transported to a laboratory, installed on three supports, prestressed, and grouted.

All the beams were reinforced with B500B reinforcing steel and with two one-strand tendons of f Ls15.7 mm/1860 MPa (area of a strand: $1.5 \mathrm{~cm}^{2}$ ) with different geometries. The first draped tendon had a geometry that produced minimum secondary effects (a concordant tendon). The second straight one, located at the bottom, was proposed with the intention of producing maximum secondary effects. The lay-out of both tendons is displayed in Fig. 2. The experimental beams were prestressed by tendons with different bonds. There were three groups of specimens altogether. The first group, beams N1 and N2, were prestressed by bonded tendons; the second group, beams $\mathrm{N} 3$ and N4, were prestressed by tendons coated with an oil emulsion for protection against corrosion (the lower bond); and the last group, beams N5 and N6, were prestressed by unbonded tendons (the monostrands). For more information about the oil emulsion applied, see Borzovic (2013). Plastic ducts with a diameter of $22 \mathrm{~mm}$ were used for each tendon. Each tendon was prestressed with a force of $200 \mathrm{kN}$.
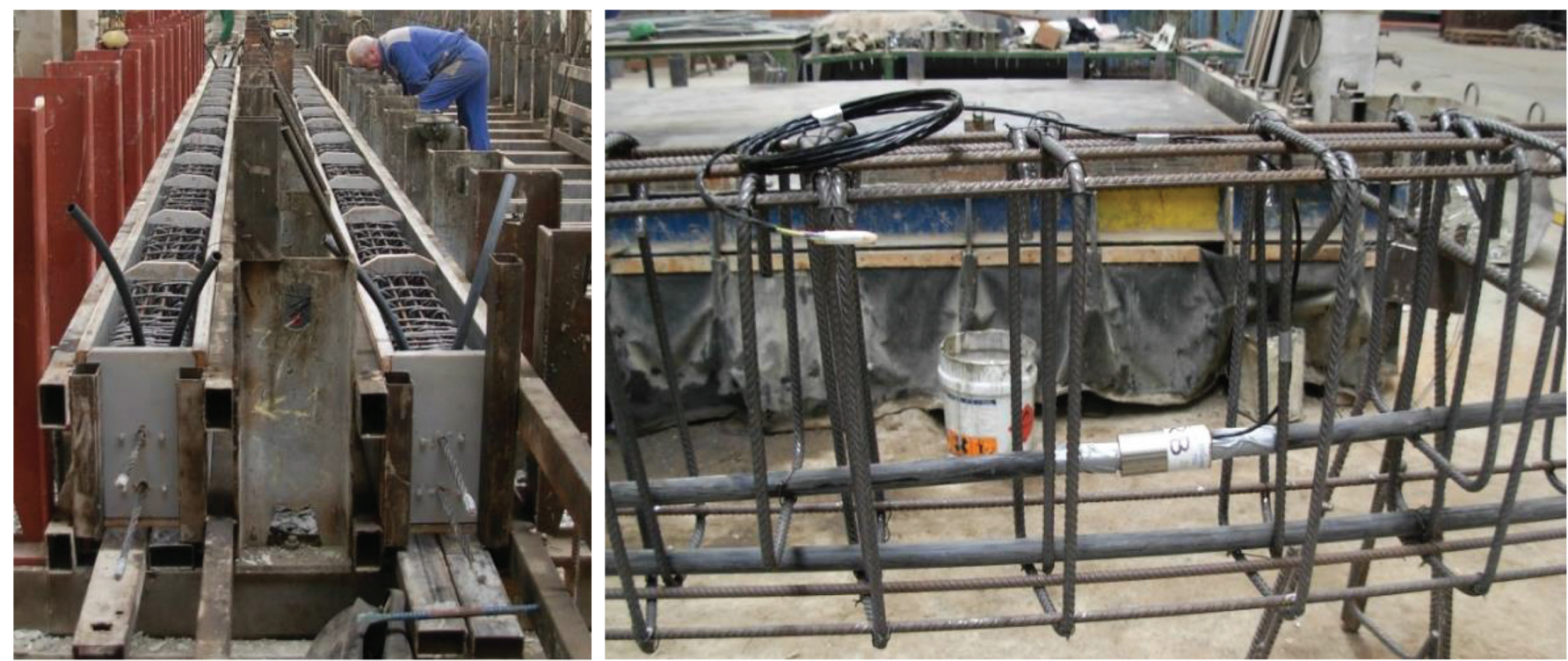

Fig. 1. Preparation and execution of experimental beams. 


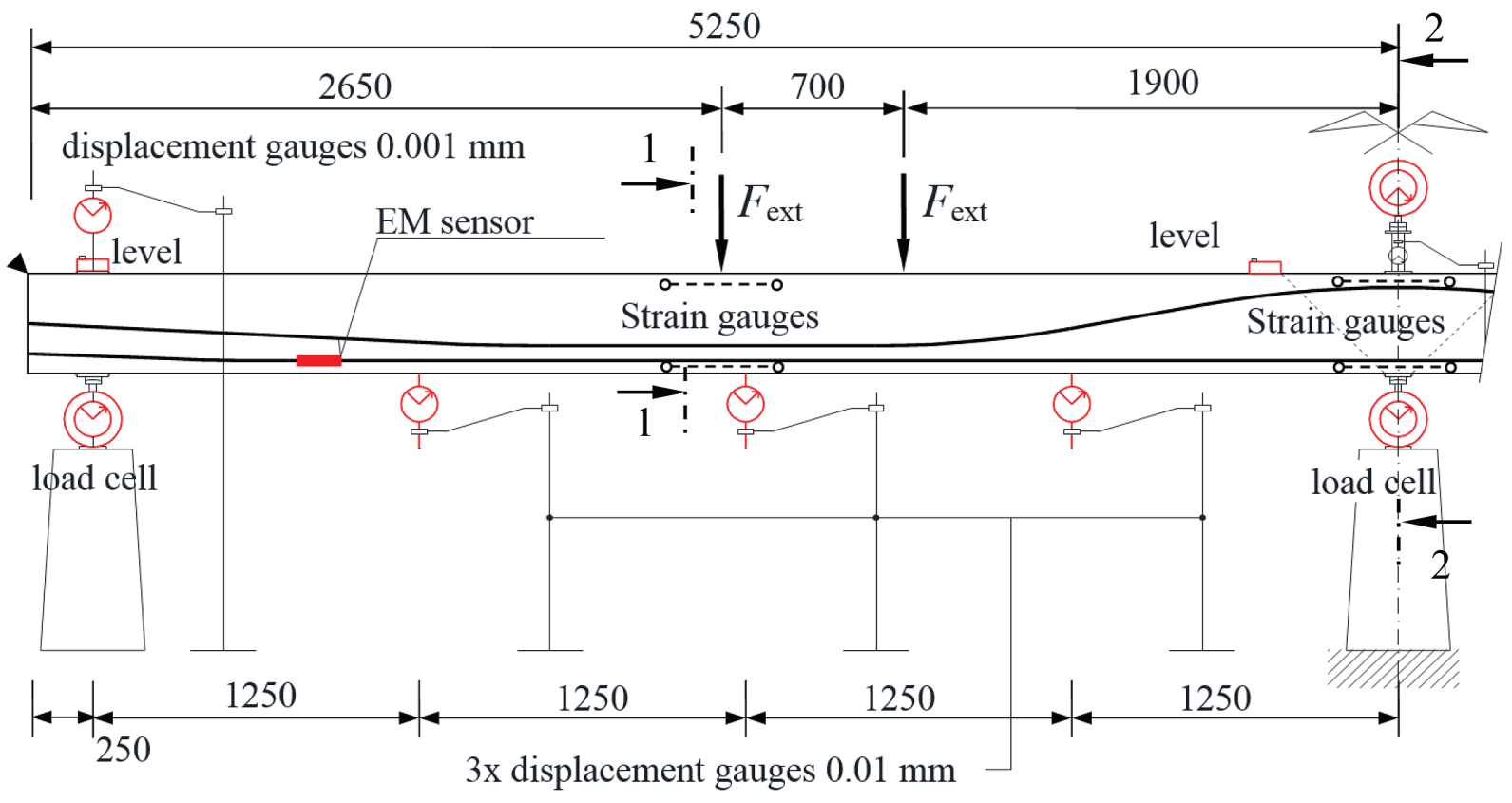

Fig. 2 The lay-outs of the tendons and measuring devices.

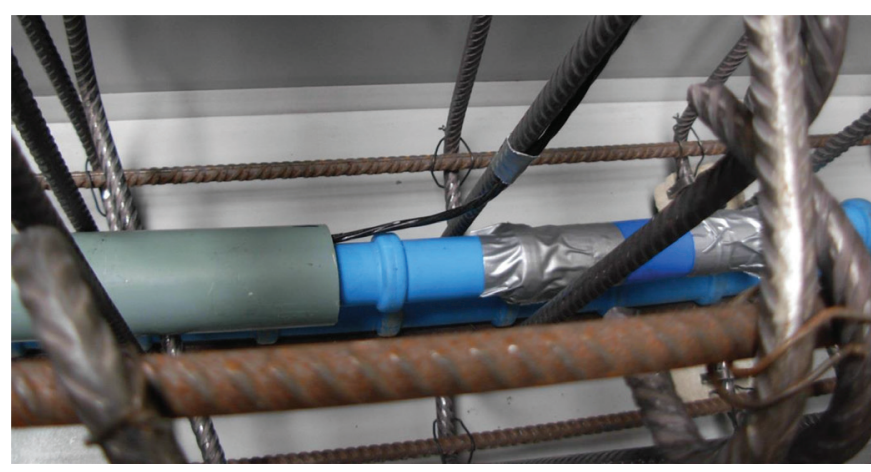

Fig. 3 Elasto-Magnetic sensors installed on the tendon.

Elasto-magnetic sensors, which were placed on each tendon on the opposite ends of a beam, were used for a detailed recording of the prestressing force, see Fig. 3.

The loading device consisted of two hydraulic jacks, one for each span. The force from the jacks was divided into two forces, see Fig. 2. The position of the hydraulic jacks was determined with the intention of creating maximum bending moments at the site of the critical cross-sections, which were located at the intermediate support and mid-span sections. The reactions were monitored with load cells, which had been put on each support. The concrete strains were measured by strain gauges attached to the beams at critical cross-sections. The settlement of the supports, displacements of the beams, and rotation at the supports were measured too. All the measuring devices used for each beam are illustrated in Fig. 2.

\section{RESULTS}

\subsection{Material properties}

The following material properties were tested: the cube strength of the concrete, the secant modulus of elasticity of the concrete, the yield strength and the tensile strength of the reinforcing steel, the modulus of elasticity and the stress-strain diagram of the reinforcing steel, the strength and $0.1 \%$ proof-stress of the prestressing steel, the modulus of elasticity and the stress-strain diagram of the prestressing steel. The material characteristics of the concrete and grouting mortar were tested at the time of the experiment. Three cubes, three prisms, and three cylinders were cast for each beam. The material properties obtained for the concrete and steel are in Tables 1 and 2, respectively.

Tab. 1 Measured material properties of the concrete - the mean values.

\begin{tabular}{|lcccccc|}
\hline Beams: & $\mathrm{N} 1$ & $\mathrm{~N} 2$ & $\mathrm{~N} 3$ & $\mathrm{~N} 4$ & $\mathrm{~N} 5$ & $\mathrm{~N} 6$ \\
\hline$f_{\mathrm{c}, \text { cube }}[\mathrm{MPa}]$ & 53.93 & 53.32 & 60.0 & 66.1 & 60.78 & 61.48 \\
$E_{\mathrm{c}}[\mathrm{GPa}]$ & 33.161 & 34.132 & 35.584 & 37.784 & 37.414 & 36.578 \\
\hline
\end{tabular}

Tab. 2 Material properties of the reinforcing and prestressing steelthe mean values.

\begin{tabular}{|ccccc|ccccc|}
\hline \multicolumn{4}{|c|}{ Reinforcing steel } & \multicolumn{4}{|c|}{ Prestressing steel } \\
\hline$\phi$ & $f_{\mathrm{y}}$ & $f_{\mathrm{t}}$ & $E_{\mathrm{s}}$ & $\varepsilon_{\mathrm{u}}$ & $f_{\mathrm{p}}$ & $f_{\mathrm{p} 0,1}$ & $\varepsilon_{\mathrm{u}}$ & $E_{\mathrm{p}}$ \\
{$[\mathrm{mm}]$} & {$[\mathrm{MPa}]$} & {$[\mathrm{GPa}]$} & {$[\mathrm{GPa}]$} & {$[\%]$} & {$[\mathrm{MPa}]$} & {$[\mathrm{MPa}]$} & {$[\%]$} & {$[\mathrm{GPa}]$} \\
12 & 508 & 601 & 212 & 11.0 & 1862 & 1516.3 & 6.0 & 195.7 \\
8 & 567 & 649 & 200 & 8.0 & & & & \\
\hline
\end{tabular}

\subsection{Prestressing forces}

The diagram of the elasto-magnetic sensor measurements over time during the prestress transfer is displayed in Fig. 4. The detailed behaviour of both tendons can be seen in this figure. The tendons in each beam were prestressed in the same order, i.e., first, the draped one, and then, the straight one. Each tendon was prestressed in a sequence with the force increasing by $50 \mathrm{kN}$, i.e., one fourth of the overall force. The losses due to slips at the anchorages and losses caused by the elastic deformation of the beams during the gradual 


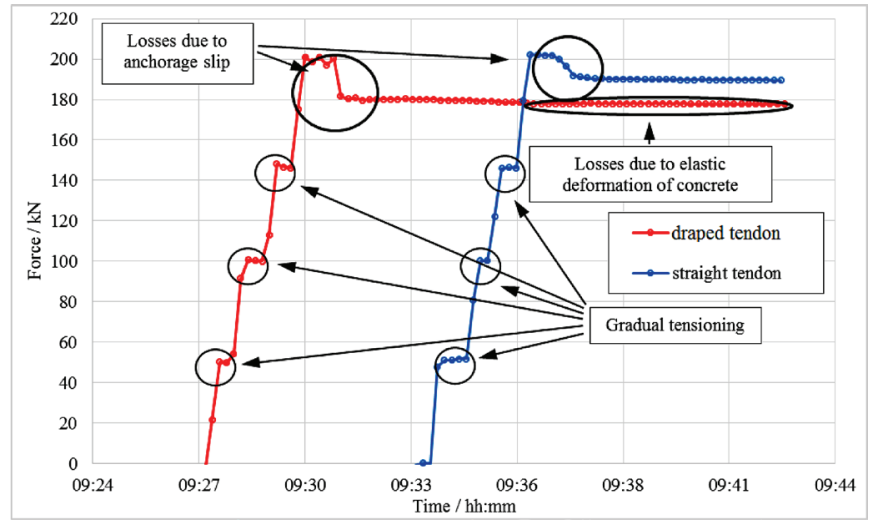

Fig. 4. Development of prestressing force in time recorded by elasto-magnetic sensor.

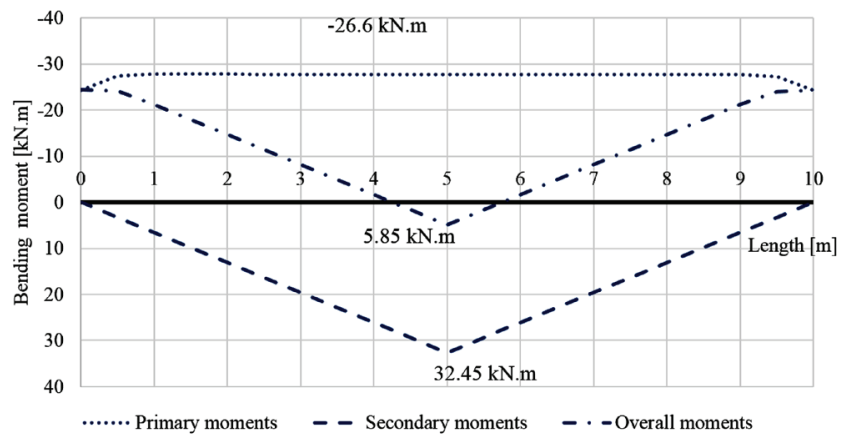

Fig. 5. Bending moments caused by the straight tendon on the N1 beam tested.

prestressing can be seen in this diagram. The results obtained from the Elasto-Magnetic sensors were used for calibrating the theoretical analysis and assessing the immediate prestress losses. The results measured from the EM sensors show good agreement between the experimental values and the values declared by the producer. The producer of the prestressing system, VSL Company, declared the average value of the anchor slip to be $6 \mathrm{~mm}$. The average value measured was $5 \mathrm{~mm}$, which is comparable with the one declared. The friction coefficient measured was 0.135 . For this type of duct (VSL PT-PLUS), it was declared to be $0.12-0.14$, see ETA-06/0006 (2011). The correctness of the prestressing system's installation was confirmed by these basic results, and the results obtained were usable for further analysis.

\subsection{Internal forces and reactions}

The bending moments due to the prestressing of the straight tendon in beam N1 are displayed in Fig. 5. They consist of the primary moments and secondary moments, which were evaluated using the reactions measured. As is shown, the secondary effects of the prestressing reached $122 \%$ of the primary effects at the intermediate support. In the case of the draped tendon, the secondary moments were negligible. The reactions measured by the load cells for each load and the corresponding bending moments at the critical cross-sections are displayed in Tables 3 to 5 for the beams selected. Table 3 shows the reactions for beam N1 with fully bonded tendons; Table 4 shows beam N3 with bonded tendons treated by the anti-corrosion emulsion; and Table 5 shows beam N5, which was prestressed by the unbonded tendons. The reactions displayed were recorded for the kinematic mechanism stage. The differences between the reactions due to the self-weight were caused by the placing of the precast beams on the load cells when it was not possible to reach the ideal horizontal level of all three supports.

Tab. 3 Reactions and corresponding bending moment - beam N1.

\begin{tabular}{|lcccc|}
\hline Bonded tendons & $\begin{array}{c}\mathrm{R} 1 \\
{[\mathrm{kN}]}\end{array}$ & $\begin{array}{c}\mathrm{R} 2 \\
{[\mathrm{kN}]}\end{array}$ & $\begin{array}{c}M_{\mathrm{ms}} \\
{[\mathrm{kN} . \mathrm{m}]}\end{array}$ & $\begin{array}{c}M_{\mathrm{is}} \\
{[\mathrm{kN} . \mathrm{m}]}\end{array}$ \\
\hline Self-weight $g_{0}$ & 6.09 & 12.58 & 6.34 & -3.58 \\
Loading devices & 0.41 & 1.19 & 0.98 & -0.21 \\
Secondary effects & 6.45 & -12.90 & 15.41 & 32.10 \\
External force 2x259.1 kN & 69.97 & 370.06 & 167.93 & -196.3 \\
Note: R1 - end supports; R2 - intermediate support & \\
$M_{\text {ms }}$ - bending moments at mid-span section (cross-section 1-1) \\
$M_{\text {is }}$ - bending moments at intermediate support (cross-section 2-2) \\
\hline
\end{tabular}

Tab. 4 Reactions and corresponding bending moment - beam N3.

\begin{tabular}{|lcccc|}
\hline $\begin{array}{l}\text { Bonded tendons with oil } \\
\text { emulsion }\end{array}$ & $\begin{array}{c}\mathrm{R} 1 \\
{[\mathrm{kN}]}\end{array}$ & $\begin{array}{c}\mathrm{R} 2 \\
{[\mathrm{kN}]}\end{array}$ & $\begin{array}{c}M_{\mathrm{ms}} \\
{[\mathrm{kN} . \mathrm{m}]}\end{array}$ & $\begin{array}{c}M_{\mathrm{is}} \\
{[\mathrm{kN} . \mathrm{m}]}\end{array}$ \\
\hline Self-weight $g_{0}$ & 7.27 & 10.57 & 9.05 & 3.39 \\
Loading devices & 0.18 & 1.65 & 0.42 & -1.37 \\
Secondary effects & 6.57 & -13.14 & 15.77 & 32.85 \\
External force 2x259.1 kN & 69.91 & 361.38 & 167.78 & -192.1 \\
Note: R1 - end supports; R2 - intermediate support & \\
$M_{\text {ms }}$ - bending moments at mid-span section (cross-section 1-1) \\
$M_{\text {is }}$ - bending moments at intermediate support (cross-section 2-2)
\end{tabular}

Tab. 5 Reactions and corresponding bending moment - beam N5.

\begin{tabular}{|lcccc|}
\hline Bonded tendons & $\begin{array}{c}\mathrm{R} 1 \\
{[\mathrm{kN}]}\end{array}$ & $\begin{array}{c}\mathrm{R} 2 \\
{[\mathrm{kN}]}\end{array}$ & $\begin{array}{c}M_{\mathrm{ms}} \\
{[\mathrm{kN} . \mathrm{m}]}\end{array}$ & $\begin{array}{c}M_{\mathrm{is}} \\
{[\mathrm{kN} . \mathrm{m}]}\end{array}$ \\
\hline Self-weight $g_{0}$ & 8.40 & 8.24 & 11.78 & 9.13 \\
Loading devices & 0.36 & 1.28 & 0.86 & -0.45 \\
& 7.09 & -14.19 & 17.03 & 35.45 \\
Secondary effects & 58.69 & 360.08 & 140.86 & -182.8 \\
External force 2x250.1 kN & & & \\
Note: R1 - end supports; R2 - intermediate support & \\
$M_{\mathrm{ms}}-$ bending moments at mid-span section (cross-section 1-1) \\
$M_{\text {is }}$ - bending moments at intermediate support (cross-section 2-2)
\end{tabular}

The measurement of the reactions allowed for the easy reconstruction of the internal forces (bending moments, shear forces), including the secondary moments in the experimental beams.

\subsection{Theoretical analysis}

The experimental specimens structurally represented continuous two-span beams. All the beams were working in an elastic state after the transfer of the prestressing force. 
a) elastic state - continuous beam

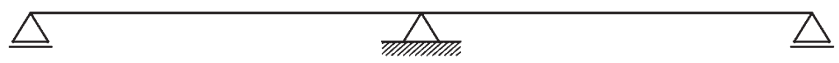

b) plastic hinge at intermediate support

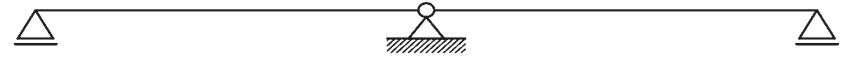

c) development of plastic hinges at mid-span sections

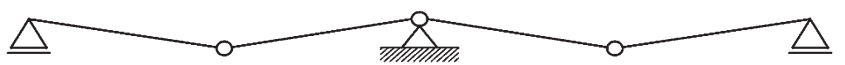

Fig. 6 Change in the structural system from a statically indeterminate beam to a kinematic mechanism.

With the gradual increase in the external forces, the bending capacity of a section at the intermediate support was reached, which resulted in the development of a plastic hinge. The statically indeterminate structure (Fig. 6a) was transformed into a sequence of isostatic members (Fig. 6b). A further increment of the external load led to the formation of a second plastic hinge (Fig. 6c) at the mid-span sections and thus to the final stage, i.e., the kinematic mechanism. This stage was assumed to be the collapse of the structure.

The loading capacity at this stage is given by the bending capacity of the critical sections, where the plastic hinges developed. In order to theoretically reconstruct the internal forces in the beams tested, it was necessary to carry out an assessment of the bending capacity of the critical cross-sections, see Fig. 7, using the mechanical properties of the structural materials obtained by testing them. The bending capacity was determined using the model, which is presented in Fig. 8 with an ultimate compressive strain of the concrete of 0.0035 .

For the strengths of the structural materials and ultimate strains of the steel, see Table 1. The active part of the prestressing force represents the axial force (1) and primary bending moment (2), which were calculated with the stress in the tendon, which includes the prestress losses. The maximum stress in a tendon for the assessment of the bending capacity was obtained from a bilinear stress-strain diagram based on the total of the pre-strain (3) and strain developed after the loading (4). The stress-strain diagram for both the prestressing and reinforcing steel were experimentally measured and directly applied in the evaluation. The stresses in the concrete under compression were determined using a non-linear stress-strain diagram, which was introduced in EC2 and Model Code 1990, and based on the strains (6).

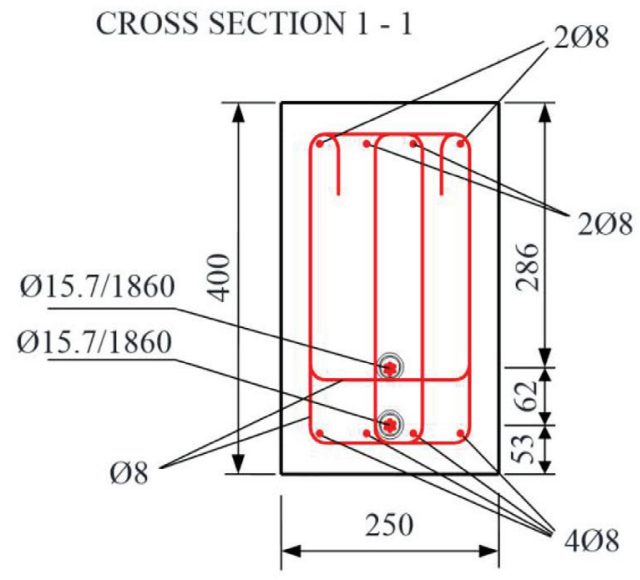

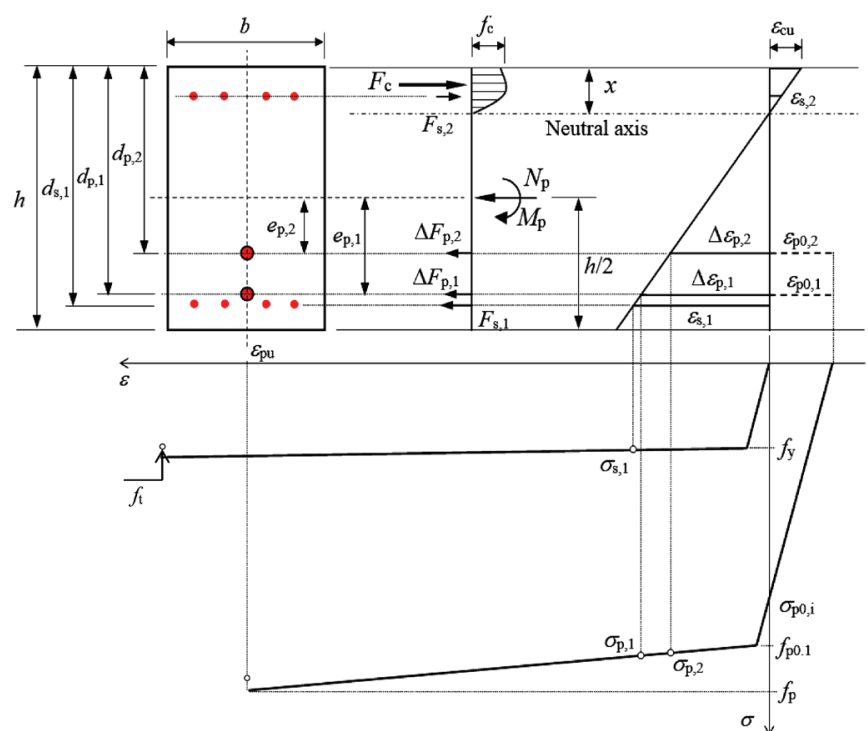

Fig. 8 Model for the assessment of the bending capacity of the crosssection with bonded tendons.

- Internal forces due to prestressing:

$$
N_{\mathrm{p}}=-\sum \sigma_{\mathrm{p} 0, \mathrm{i}} A_{\mathrm{p}, \mathrm{i}} ; M_{\mathrm{p}}=-\sum \sigma_{\mathrm{p} 0, \mathrm{i}} A_{\mathrm{p}, \mathrm{i}} e_{\mathrm{p}, \mathrm{i}}
$$

- Pre-strains:

$$
\varepsilon_{\mathrm{p} 0, \mathrm{i}}=\frac{\sigma_{\mathrm{p} 0, \mathrm{i}}}{E_{\mathrm{p}}}
$$

- Strains in the prestressing tendons that developed due to the deformation of the cross-section:

$$
\Delta \varepsilon_{\mathrm{p}, \mathrm{i}}=\frac{\varepsilon_{\mathrm{cu}}}{x}\left(d_{\mathrm{p}, \mathrm{i}}-x\right)
$$

- Strains in the reinforcing steel:

$$
\varepsilon_{\mathrm{s}, \mathrm{i}}=\frac{\varepsilon_{\mathrm{cu}}}{x}\left(d_{\mathrm{s}, \mathrm{i}}-x\right)
$$

- Strains in the concrete under compression at distance " $z$ " measured from the extreme fiber:

$$
\varepsilon_{\mathrm{c}}(z)=\frac{\varepsilon_{\mathrm{cu}}}{x}(x-z)
$$

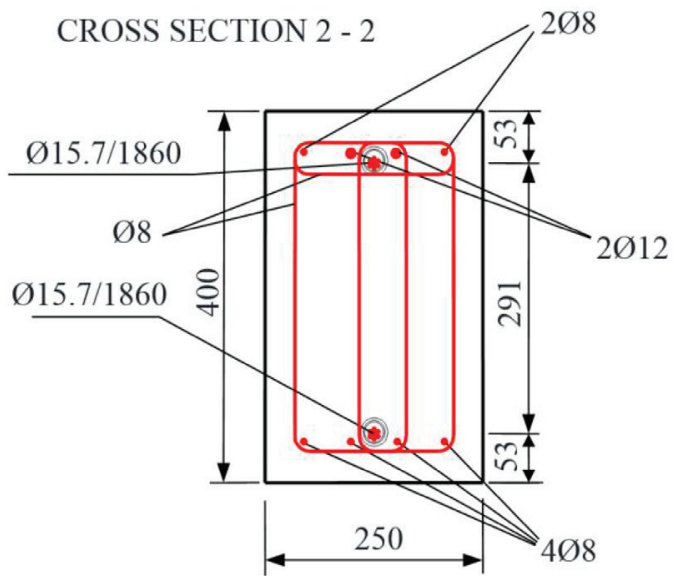

Fig. 7 Layouts of critical cross-sections. 
- Forces in the prestressing tendons that developed after loading: with limit $0 £ \mathrm{~s}_{\mathrm{p}, \mathrm{i}} £ f_{\mathrm{p}}$

$$
\Delta F_{\mathrm{p}, \mathrm{i}}=\left(\sigma_{\mathrm{p}, \mathrm{i}}-\sigma_{\mathrm{p} 0, \mathrm{i}}\right) A_{\mathrm{p}, \mathrm{i}} \text { with limits } 0 \leq \sigma_{\mathrm{p}, \mathrm{i}} \leq f_{\mathrm{p}}
$$

- Forces in the reinforcing steel:

$$
F_{\mathrm{s}, \mathrm{i}}=\sigma_{\mathrm{s}, \mathrm{i}} A_{\mathrm{s}, \mathrm{i}} \text { with limits }-f_{\mathrm{t}} \leq \sigma_{\mathrm{s}, \mathrm{i}} \leq f_{\mathrm{t}}
$$

- Horizontal force in the concrete:

$$
F_{\mathrm{c}}=\int_{0}^{x} b \sigma_{\mathrm{c}}(z) d z
$$

The position of the neutral axis " $x$ " was calculated from the equilibrium of the horizontal forces.

$$
F_{\mathrm{c}}-\sum F_{\mathrm{s}, \mathrm{i}}-\sum \Delta F_{\mathrm{p}, \mathrm{i}}-N_{\mathrm{p}}=0
$$

The bending capacity was assessed from the moment condition (11). Because the outputs of the FEM computer analysis usually provide the effects of prestressing in hyperstatic structures as one final value, which includes both the primary and secondary effects, it is necessary to stress that the bending capacity expressed by (11) does not include any secondary bending moments. The secondary effects are assumed to be on the side of the load.

$$
M_{\mathrm{R}}=F_{\mathrm{c}}\left(h / 2-z_{\mathrm{c}}\right)+\sum F_{\mathrm{s}, \mathrm{i}}\left(d_{\mathrm{s}, \mathrm{i}}-h / 2\right)+\sum \Delta F_{\mathrm{p}, \mathrm{i}}\left(d_{\mathrm{p}, \mathrm{i}}-h / 2\right)+M_{\mathrm{p}}=0
$$

The model was fully applied for the beams prestressed by the bonded tendons (beams N1, N2) and by the tendons treated with the anti-corrosion emulsion (beams N3, N4). In the case of the beams prestressed by the unbonded tendons, the calculation of the bending capacity is more complex, because the forces in the tendons are influenced by the deformation of the whole structure and not only by the deformation of an analysed cross-section. Several models to determine the increment of the prestressing force in the unbonded tendons due to the external load were proposed, but they always represent an approximation of the degree of accuracy, that is acceptable for design and safety verifications but problematic for evaluations of experiments. The forces in the tendons directly measured by the EM sensors were therefore used for the assessment of the bending capacity in the beams with the unbonded tendons (beams N5, N6). In the case of the beams with bonded tendons, the position of the sensors did not allow for the direct measurement of the prestressing force at the critical cross-sections.

The experiments have shown that the application of the oil emulsion for the protection of the strands from corrosion did not significantly influence the behaviour of the beams at the level of service as well as of the ultimate load in comparison with the beams prestressed by strands without this treatment. Similar results have also been presented by Vitek (2015). The assessed bending capacity of the mid-span sections for the beams with bonded tendons and the bonded tendons with the anti-corrosion emulsion reached a value of 192.3 kN.m (191,3 kN.m); for the beams with unbonded tendons, it was $167.9 \mathrm{kN} . \mathrm{m}$. In the case of the sections at the intermediate support, it was $150.8 \mathrm{kN} . \mathrm{m}(149.8 \mathrm{kN} . \mathrm{m})$ for the bonded and $136.3 \mathrm{kN} . \mathrm{m}$ for the unbonded tendons. The values in the brackets were obtained using Response - 2000 software.

\subsection{Evaluation of the experiments}

The evaluation of the experiment is based on the reconstruction of the internal forces during the loading of the experimental speci- mens. The reactions known due to the self-weight, the weight of the devices for the loading, and the jack forces with the measurement of the reactions in the supports allowed for the separation of each action, including the secondary effects of the prestressing. In this way, it was possible to determine the bending moments at any section of the experimental beams with and without the secondary moments.

If secondary effects are present in the system after the development of the kinematic mechanism, then any bending moments due to the external loads with secondary moments should be equal to or close to the bending capacity. On the other hand, if the secondary effects disappear, then the bending moments without this effect should be closer to the bending capacity.

A comparison of the bending capacities with the bending moments measured at the critical cross-sections calculated with and without the secondary effects is displayed in Tables 6 to 8. Similar comparisons for each beam are also displayed in Figs. 9 and 10. The charts clearly indicate that in each beam, the bending moments with secondary effects were much closer to the bending capacities than the moments without these effects. It can therefore be concluded that the

\begin{tabular}{|c|c|c|c|c|c|}
\hline \multirow{2}{*}{$\begin{array}{l}\text { Beams } \\
\text { with bonded } \\
\text { tendons }\end{array}$} & \multirow[b]{2}{*}{$\begin{array}{c}\boldsymbol{M}_{\mathbf{R}} \\
{[\mathrm{kN} . \mathrm{m}]}\end{array}$} & \multicolumn{2}{|c|}{ Beam N1 } & \multicolumn{2}{|c|}{ Beam N2 } \\
\hline & & $\begin{array}{c}\boldsymbol{M}_{\mathrm{E}, \mathbf{a}} \\
{[\mathrm{kN} . \mathrm{m}]}\end{array}$ & $\begin{array}{c}\boldsymbol{M}_{\mathrm{E}, \mathbf{b}} \\
{[\mathrm{kN} . \mathrm{m}]}\end{array}$ & $\begin{array}{c}\boldsymbol{M}_{\mathbf{E}, \mathbf{a}} \\
{[\mathrm{kN} . \mathrm{m}]}\end{array}$ & $\begin{array}{c}\boldsymbol{M}_{\mathbf{E}, \mathbf{b}} \\
{[\mathrm{kN} . \mathrm{m}]}\end{array}$ \\
\hline Section 1-1 & 192.3 & 190.7 & 174.9 & 195.2 & 179.3 \\
\hline Section 1-1 & $100 \%$ & $99.2 \%$ & $91.0 \%$ & $101.5 \%$ & $93.2 \%$ \\
\hline Section 2-2 & -150.8 & -168.8 & -200.9 & -150.1 & -183.2 \\
\hline Section 2-2 & $100 \%$ & $111.4 \%$ & $133.2 \%$ & $99.5 \%$ & $121.5 \%$ \\
\hline \multicolumn{6}{|c|}{$\begin{array}{l}\boldsymbol{M}_{\mathrm{E}, \mathrm{a}}-\text { Experimentally obtained bending moments with secondary } \\
\text { effects }\end{array}$} \\
\hline \multicolumn{6}{|c|}{$\begin{array}{l}\boldsymbol{M}_{\mathrm{E}, \mathbf{b}} \text { - Experimentally obtained bending moments without } \\
\text { secondary effects }\end{array}$} \\
\hline
\end{tabular}
secondary moments were present in the system even after the development of the kinematic mechanism.

Tab. 6 Comparison between theoretical and experimental results -

\begin{tabular}{|c|c|c|c|c|c|}
\hline \multirow{2}{*}{$\begin{array}{l}\text { Beams with } \\
\text { partially } \\
\text { bonded } \\
\text { tendons }\end{array}$} & \multirow[b]{2}{*}{$\begin{array}{c}\boldsymbol{M}_{\mathrm{R}} \\
{[\mathrm{kN} \cdot \mathrm{m}]}\end{array}$} & \multicolumn{2}{|c|}{ Beam N3 } & \multicolumn{2}{|c|}{ Beam N4 } \\
\hline & & $\begin{array}{c}\boldsymbol{M}_{\mathbf{E}, \mathbf{a}} \\
{[\mathrm{kN} . \mathrm{m}]}\end{array}$ & $\begin{array}{c}\boldsymbol{M}_{\mathbf{E}, \mathbf{b}} \\
{[\mathrm{kN} . \mathrm{m}]}\end{array}$ & $\begin{array}{c}\boldsymbol{M}_{\mathbf{E}, \mathbf{a}} \\
{[\mathrm{kN} . \mathrm{m}]}\end{array}$ & $\begin{array}{c}\boldsymbol{M}_{\mathbf{E}, \mathbf{b}} \\
{[\mathrm{kN} . \mathrm{m}]}\end{array}$ \\
\hline Section 1-1 & 192.3 & 193.0 & 177.3 & 195.6 & 178.9 \\
\hline Section 1-1 & $100 \%$ & $100.4 \%$ & $92.2 \%$ & $101.7 \%$ & $93.0 \%$ \\
\hline Section $2-2$ & -150.8 & -157.2 & -190.1 & -151.3 & -186.3 \\
\hline Section 2-2 & $100 \%$ & $104.3 \%$ & $126.0 \%$ & $100.3 \%$ & $123.5 \%$ \\
\hline \multicolumn{6}{|c|}{$\boldsymbol{M}_{\mathrm{R}}-$ Theoretical bending capacity } \\
\hline \multicolumn{6}{|c|}{$\begin{array}{l}\boldsymbol{M}_{\mathrm{E}, \mathrm{a}} \text { - Experimentally obtained bending moments with secondary } \\
\text { effects }\end{array}$} \\
\hline \multicolumn{6}{|c|}{$\begin{array}{l}\boldsymbol{M}_{\mathbf{E}, \mathbf{b}}-\text { Experimentally obtained bending moments without } \\
\text { secondary effects }\end{array}$} \\
\hline
\end{tabular}
beams N1, N2.

Tab. 7 Comparison between theoretical and experimental results beams N3, N4. 
Tab. 8 Comparison between theoretical and experimental results beams N5, N6.

\begin{tabular}{|lccccc|}
\hline $\begin{array}{l}\text { Beams with } \\
\text { unbonded } \\
\text { tendons }\end{array}$ & $\boldsymbol{M}_{\mathrm{R}}$ & $\boldsymbol{M}_{\mathrm{E}, \mathrm{a}}$ & $\boldsymbol{M}_{\mathrm{E}, \mathbf{b}}$ & $\boldsymbol{M}_{\mathrm{E}, \mathbf{a}}$ & $\boldsymbol{M}_{\mathbf{E}, \mathbf{b}}$ \\
& {$[\mathrm{kN} . \mathrm{m}]$} & {$[\mathrm{kN} . \mathrm{m}]$} & {$[\mathrm{kN} . \mathrm{m}]$} & {$[\mathrm{kN} . \mathrm{m}]$} & {$[\mathrm{kN} . \mathrm{m}]$} \\
\hline Section 1-1 & 167.9 & 170.5 & 153.5 & 172.6 & 156.3 \\
Section 1-1 & $100 \%$ & $101.6 \%$ & $91.4 \%$ & $102.8 \%$ & $93.1 \%$ \\
Section 2-2 & -136.3 & -138.3 & -173.2 & -129.7 & -163.7 \\
Section 2-2 & $100 \%$ & $101.5 \%$ & $127.1 \%$ & $95.2 \%$ & $120.1 \%$ \\
$\boldsymbol{M}_{\mathbf{R}}-$ Theoretical bending capacity \\
$\boldsymbol{M}_{\mathbf{E}, \mathbf{a}}$ - Experimentally obtained bending moments with secondary \\
effects \\
$\boldsymbol{M}_{\mathbf{E}, \mathbf{b}}$ - Experimentally obtained bending moments without \\
secondary effects
\end{tabular}

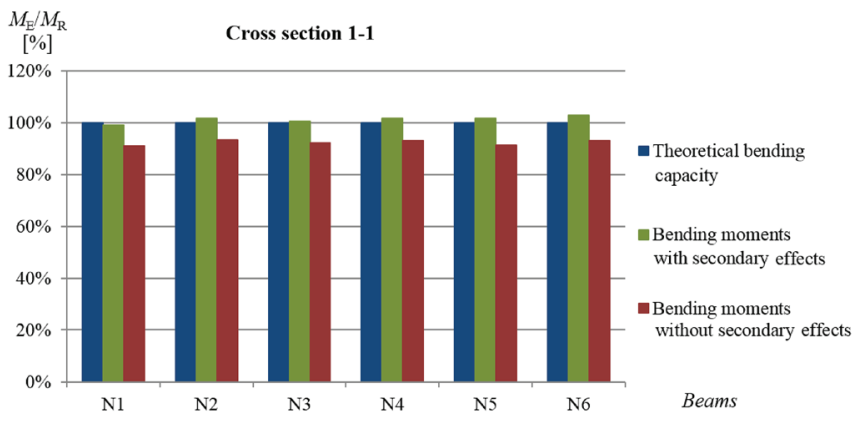

Fig. 9 Comparison of the bending capacities with the measured bending moments for cross-section 1-1.

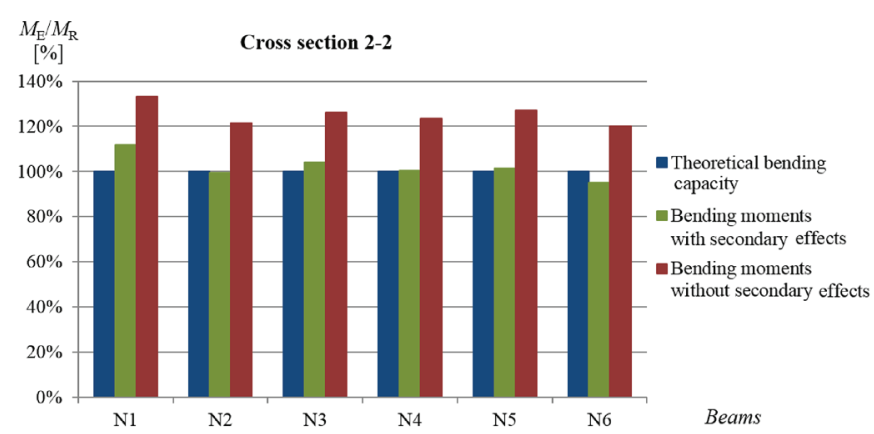

Fig. 10 Comparison of the bending capacities with the measured bending moments for cross-section 2-2.

\subsection{Results concerning the bond behavior of the prestressed beams}

All the beams failed due to the crushing of the concrete in the compression cord at the sections within the plastic hinges without respect to the bonds of the tendons.

The major difference between the beams with bonded tendons (N1-N4) and the beams prestressed by monostrands was the distribution and width of the cracks along the beams in the areas exposed to tension. The cracks were evenly distributed in the case of the beams with bonded tendons. In beams N5 and N6 with unbonded tendons, one major crack developed in the critical sections due to the cracking moment. With the increasing load, the width of the major cracks grew

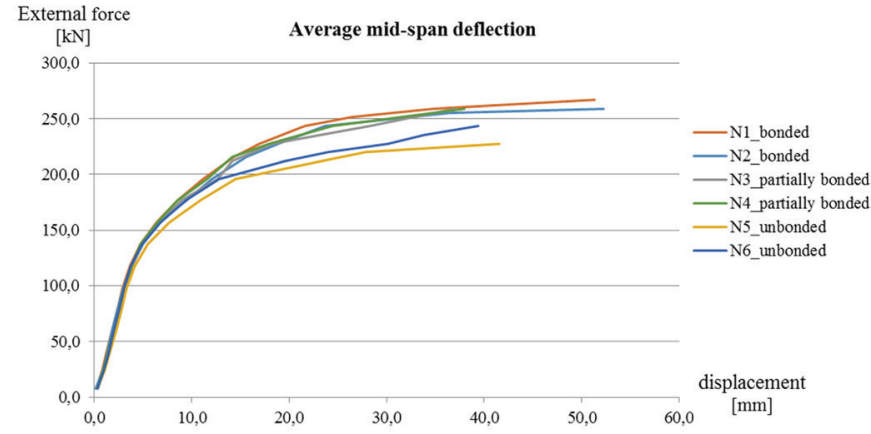

Fig. 11 Diagram of the mid-span displacement vs. the external load.

much faster than the neighboring ones. The major cracks had a much greater width than the others prior to the beam's failure, which was accompanied by the rupture of the ordinary reinforcement.

In the case of beams N3 and N4 with tendons treated by the anticorrosion emulsion, the crack widths and mid-span displacements were comparable with the results obtained from beams N1 and N2, which were prestressed by the tendons with full bonds. The staggered loss of the bonds due to the load approaching the ultimate value in beams N3 and $\mathrm{N} 4$ caused a small increment of the deformation shortly prior to the failure in comparison with beams N1 and N3, see Fig. 11. In the case of the beams with monostrands, the displacements grew faster compared to the beams with bonded tendons since the experimental load reached $60 \%$ of the ultimate load for the beams with a bond.

The varied behavior of the prestressed beams with different bonds of the tendons is quite visible in the records of the elasto-magnetic sensors. The sensors were placed on tendons approximately $800 \mathrm{~mm}$ from the ends of the beams, so they were not located on plastic hinges.

The record of the prestressing force's development during the loading is in Fig. 12 for the fully bonded tendons. Only a very small increment of force was observed for the draped tendons, and it was a little bit higher for the straight tendons with a small jump up when the kinematic mechanism developed.

This indicates that the local increment of the prestressing force is mainly concentrated at the critical cross-sections and, thanks to the high bond, is not transferred to the sections with the EM sensors located $800 \mathrm{~mm}$ from the beam ends. The record of the prestressing force in the tendons with a partial bond is shown in Fig. 13. The bond failure was reached here with a load representing approximately $80 \%$ of the external load needed for the development of the kinematic mechanism. The force in the straight tendon suddenly jumped from $194 \mathrm{kN}$ to $206 \mathrm{kN}$; in the case of the deviated tendon, the increment was smaller by only $5.5 \mathrm{kN}$. However, major increments in the prestressing force were again concentrated in the critical sections. The last chart (Fig. 14) presents the development of the prestressing force in the unbonded tendons. Each loading step is quite visible since the first cracks developed in the beam. Due to the low friction in the monostrands, similar prestressing forces can be expected along the whole length of the tendons. The increment of the prestressing force was influenced here by the deformation of the whole structure.

\section{CONCLUSIONS}

The effect of changes in a structural system on the secondary effects of prestressing due to the development of plastic hinges was investigated on six experimental post-tensioned continuous beams. The beams were subjected to a step-by-step increasing external load, which created several plastic hinges in the system with the final stage as a kinematic mechanism, see fig.15. The distribution of the internal 


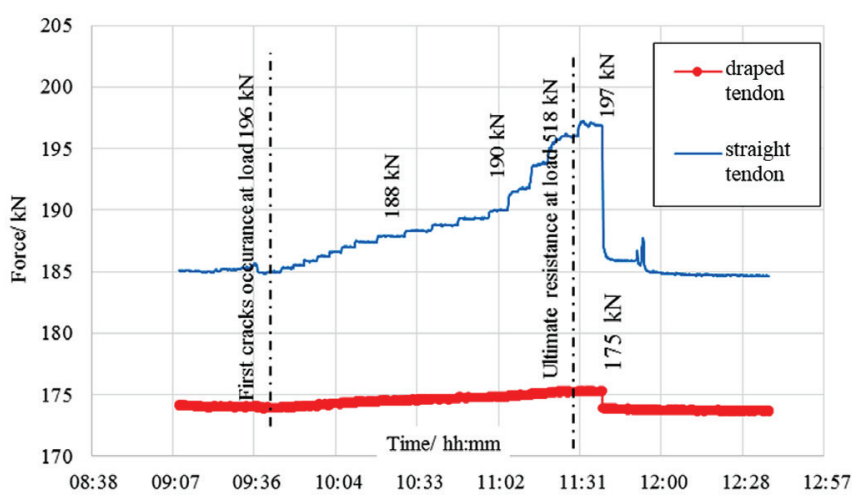

Fig. 12 Record of EM sensors during the experiment, beam with bonded tendons.

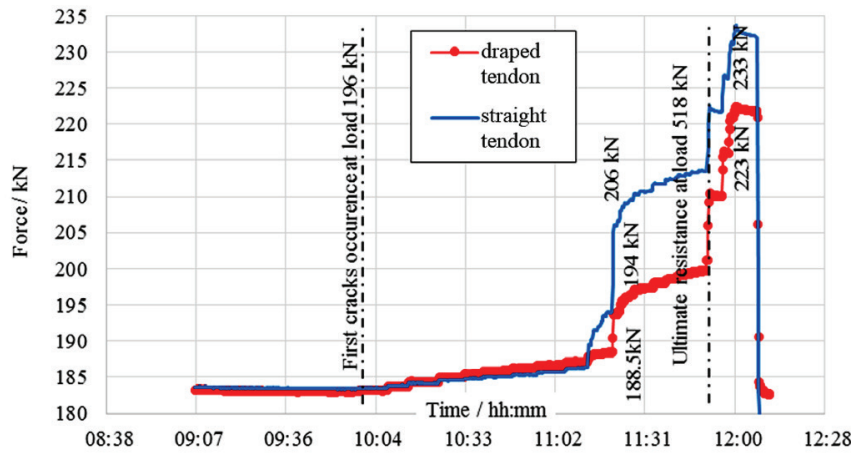

Fig. 13 Record of EM sensors during the experiment, beam with partially bonded tendons.

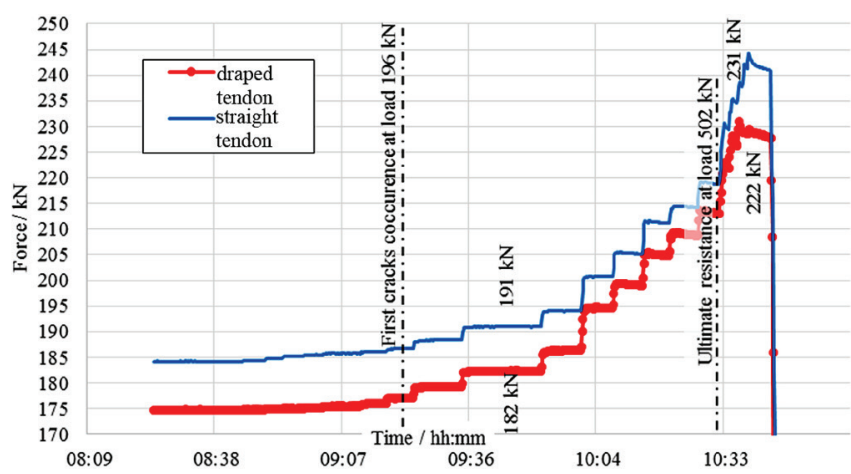

Hig. 14. Kecord of EM sensors during the experiment, beam with unbonded tendons. forces, including the secondary moments for each loading step, was constructed with the reactions measured at each support. A comparison of the bending moments with and without the secondary moments with the bending capacities assessed at the critical cross-sections showed that the secondary effects did not disappear after the transition of the structural system from a hyperstatic to an isostatic one or to a kinematic mechanism. In the case of beams with bonded tendons, the average difference between the theoretical flexural resistance and the experimental bending moment obtained without secondary effects in cross-section $1-1$ was $-7.9 \%$, while in the case of the assumed secondary effects, the difference decreased to -0.4 $\%$. For cross-section 2-2, the differences were even more striking. In the case without secondary effects, the difference was $27.4 \%$, while with the assumed secondary effects, the difference was $5.5 \%$. Similar results were obtained for the other beams.

Based on the results presented, it can be concluded that the secondary effects of prestressing represent permanent action on a structure. Therefore, they have to be assumed in all combinations of actions used for the verification or control of a structure. The designer should not rely on the redistribution of internal forces due to secondary effects in the case of a plastic or nonlinear analysis of a structure at its ULS.

The application of oil emulsions on strands for their protection against corrosion did not significantly influence the behavior of the beams subjected to the service and even to the ultimate load. All four beams failed due to almost the same load. The development of deflections at the mid-span sections and crack widths were similar for all the beams with bonded tendons. The loss of the bond was recorded by the EM sensors shortly prior to the development of the kinematic mechanism in the case of the beams with a full bond. In the case of the beams with a reduced bond, the loss was observed when the load reached $80 \%$ of the ultimate load. In the case of the beams prestressed by the monostrands, one major crack developed in each critical section. Lower flexural stiffness and larger mid-span deflections were observed when the experimental load reached $60 \%$ of the ultimate load.

\section{Acknowledgements}

This work was supported by the Slovak Research and Development Agency under Contract No. APVV-0442-12 and by Scientific Grant Agency of the Ministry of Education, science, research and sport of the Slovak Republic and the Slovak Academy of Sciences No $1 / 0456 / 17$. The authors gratefully acknowledge the provision of the prestressing anchors by VSL/CZ/.

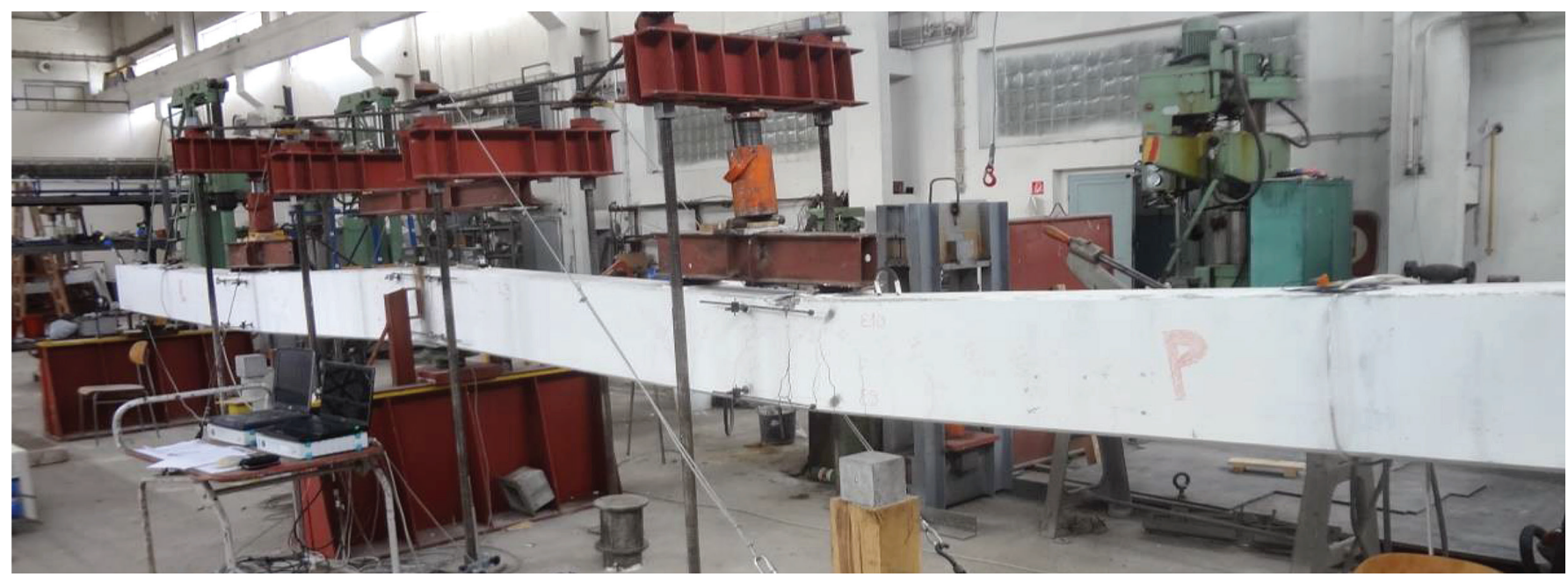

Fig.15 Prestressed beam changed into kinematic mechanism. 


\section{REFERENCES}

Andrew, R., P. - Witt, P. (1951) Prestressed Concrete - Statically Indeterminate Structures, A Symposium on Prestressed Concrete Statically Indeterminate Structures, 24-25 Sept., 1951. Papers and a discussion at a symposium organized by the Cement and Concrete Association in conjunction with the Prestressed Concrete Development Group at the Institution of Civil Engineers, London

Aravinthan,T. - Witchukreangkrai - Eakarat - Mutsuyoshi, H. (2005) Flexural Behavior of Two-Span Continuous Prestressed Concrete Girders with Highly Eccentric External Tendons, ACI Structural Journal/May-June 2005, pp. 402-411

Borzovic,V. - Laco, J. (2013) Bond of Strands Coated With Different Anticorrosion Agents. Proceedings of $20^{\text {th }}$ Czech Concrete Days , 27-28.11.2013, Hradec Kralove, Czech Rep.

Burgoyne, Ch. (2005) Analysis of Continuous Prestressed Concrete Beams, www.civ.eng.cam.ac.uk/cjb/papers/cp71.pdf

Laco, J. (2015) Bond behavior of prestressing strands coated with corrosion protection emulsifiable oil. Proceedings of The 11th Central European Congress on Concrete Engineering, Innovative Concrete Technology in Practice, 1-2 Oct. 2015, Hainburg, Austria, 2015, pp. 346-349
Mattock, A. H. (1983) Secondary moments and moment redistribution in ACI318-77 Code. In M. Z. Cohn (Ed.), Int. Symposium on Nonlinearity and Continuity in Prestressed Concrete, Vol. 3, pp. 27-48. University of Waterloo, Ontario, Canada.

Moravčík, M. (2017) Design of prestressed concrete structures according to European standards edited by ŽU in Žilina, 2017, press EDIS - publishing center ŽU, ISBN 978-80-554-1354-9

Vitek, J. - Čitek, D. (2015) Consequences of Reduced Bond of Prestressing Strands. Proceedings of The 11th Central European Congress on Concrete Engineering, Innovative Concrete Technology in Practice, 1-2.10. 2015, Hainburg, Austria, pp. 20 - 23

ETA-06/0006 (2011) VSL International Ltd.: European Technical Approval No. ETA-06/0006

Response-2000. Reinforced Concrete Sectional Analysis using the Modified Compression Field Theory, program written by Evan C.Bentz, University of Toronto 